\title{
Foreword to special COVID-19 edition for Irish Journal of Psychological Medicine
}

\author{
William Flannery \\ Department of Adult Psychiatry, Mater Misericordiae University Hospital, Dublin 7
}

The mission of the College of Psychiatrists of Ireland is to promote excellence in the practice of psychiatry, which the College fulfills through education of trainee psychiatrists, provision of continuous professional development, and advocacy of those who suffer from mental illness, insisting on best practice in education and Mental Health services. COVID-19 caused by a new strain of coronavirus cuts through all of this. This is why the Irish Journal of Psychological Medicine special COVID-19 issue is to be strongly welcomed, as it helps us advance into this changed mental health landscape.

This virus has shown why there has to be parity of esteem for mental illness. We were concerned before the crisis that those with mental illness would be more vulnerable and we are observing the consequences of that, especially in residential mental health units. There is an impact on mental health as well as on physical health in those infected with COVID-19 and both need to be treated for a full recovery. The College has advocated with the operational section and the regulatory section of the Health Service to ensure that services have the necessary resources to do this.

The General Public are to be credited with how the public health measures have been adhered to, and likewise credit to healthcare staff in how they have responded to the crisis. There is no doubt lives have been saved, but the stress of doing all of this will have an impact on mental health. The College believes that the best way to acknowledge this hard work is to have interventions that respond effectively to this stress and to its consequences for mental health. It is a relief then that we can look to the official journal of the
College for the developing evidence base for the mental health consequences of COVID-19.

The College itself has had to adapt with measures to prevent the spread of infection. Many of the training processes are now done remotely. There are a number of challenges: how to deliver training, how to ensure that training remains of a high standard, adapting clinical skills to social distancing and looking at telepsychiatry as a competency. Similar challenges are there for continuous professional development and the delivery of Mental Health Services. The College website now acts as a resource for emerging information on the mental health consequences of COVID-19. In particular, the video series done by College members on supporting families of young people with mental illness is to be commended.

COVID-19 is infectious and destructive, as is the fear it brings. Bertrand Russell said "to conquer fear is the beginning of wisdom." A core value of the College is wisdom, which is very present here in the following editorial and research. Finally, I want to acknowledge the hard work of Dr John Lyne, Professor Fiona McNicholas, Dr Blánaid Gavin, and the College Staff working with the Journal and to thank them for this special COVID-19 issue.

Dr William Flannery

President of the College of Psychiatrists of Ireland

\section{Conflict of interests}

None. 